\title{
DESAIN KARAKTER TOKOH PROKLAMATOR DALAM SEJARAH PERUMUSAN NASKAH PROKLAMASI INDONESIA
}

\author{
Andhika April Ryansyah ${ }^{1)}$, Winny Gunarti W. W. ${ }^{2)}$, Febrianto Saptodewo ${ }^{3)}$ \\ Program Studi Desain Komunikasi Visual, \\ Fakultas Bahasa dan Seni, Universitas Indraprasta PGRI \\ Jl. Nangka No. 58 C, Tanjung Barat, Jakarta 12530, Indonesia \\ dhikaryansyah23@gmail.com
}

\begin{abstract}
Abstrak
Dengan memperkenalkan dan menceritakan kembali sejarah perumusan naskah proklamasi kepada remaja sebagai salah satu peristiwa paling bersejarah bangsa Indonesia, maka diperlukan sebuah media informasi pengenalan para tokoh yang terlibat dalam sejarah perumusan naskah proklamasi tersebut. Media informasi yang saat ini paling mampu mendapatkan antusias remaja adalah media visual yang modern. Metode penelitian yang digunakan adalah kualitatif dengan mengumpulkan data visual berupa foto. Karakter tokoh proklamator dirancang dengan gaya visual semi kartun dengan mengacu pada data visual seperti patung dan data gambar pada literatur, agar perancangan karakter tidak terlampau jauh pada tokoh aslinya.
\end{abstract}

Kata Kunci: karakter tokoh, proklamasi, kartun

\begin{abstract}
By introducing and retelling the history of formulating the proclamation manuscript to the youth as one of the most historical events of the nation of Indonesia, it is necessary an information media introduction of the figures involved in the history Formulation of the Proclamation manuscript. Media information that is currently most capable of gaining teenage enthusiasm is a modern visual medium. The research method used is qualitative by collecting visual data in the form of photographs. The character is designed in a semi-cartoony visual style concerning visual data such as sculpture and image data in the literature so that the character's design is not too far from the original figure.
\end{abstract}

Keywords: character figures, proclamation, cartoons.

Correspondence author: Andhika April Ryansyah, dhikaryansyah23@gmail.com, Jakarta, and Indonesia

\section{PENDAHULUAN}

Pada dasarnya sejarah adalah rangkaian perjuangan umat manusia dalam rangka perjuangan mempertahankan eksistensinya, dan untuk mencapai cita-citanya. Demikian pula halnya dengan perjuangan bangsa Indonesia. Sejak "bangsa Indonesia" mulai ada, sejak itu pula perjuangan 
bangsa telah ada. Hal ini berarti pada waktu berdirinya kerajaan Kutai, Tarumanegara, Matraman, Aceh, Makasar, dan sebagainya, perjuangan "bangsa Indonesia" telah berlangsung. Sejak munculnya bangsa "Barat" di Indonesia, terutama sejak berhasilnya kolonialisme Belanda menanamkan kekuasaanya, perjuangan bangsa Indonesia terutama ditunjukan untuk mengusir kaum penjajah (Susilo, 1991: 1)

Pernyataan kemerdekaan itu diumumkan ke seluruh penjuru dunia, sejak itu bangsa Indonesia telah berdiri sama tinggi dengan bangsa-bangsa merdeka di atas dunia. Kemerdekaan Indonesia itu tidak datang dengan begitu saja, bak salju turun dari angkasa, tetapi kemerdekaan Indonesia itu adalah suatu klimaks dari suatu proses perjalanan sejarah perjuangan yang panjang. Proklamasi itu adalah titik kulminasi dari cita-cita kemerdekaan Indonesia yang mencapai titik tertingginya pada tanggal 17 Agustus 1945 (Indra \& Marthabaya, 1989: 21).

Peristiwa perumusan naskah proklamasi, terjadi di gedung bekas kediaman Laksamana Muda Laut Tadashi Maeda, yang pada waktu itu bernama jalan Meiji dori No. 1 Jakarta, dan kini menjadi kaitan sejarah yang sangat penting bagi bangsa Indonesia, karena peristiwa itu tidak dapat dipisahkan dari peristiwa Proklamasi (Susilo, 1991: 3). Sayangnya, generasi saat ini masih ada bahkan banyak yang tidak mengetahui bagaimana kronologis dan tokoh-tokoh yang terlibat dalam perumusan naskah proklamasi dan lebih menyukai dan tertarik dengan cerita-cerita dan budaya asing.

Salah satu cara yang dapat dilakukan untuk kronologis dan tokoh yang terlinat dalam peristiwa tersebut adalah dengan cara membuat sebuah media informasi bagi para remaja. Salah satunya dengan sebuah perancangan karakter para tokoh yang terlibat dalam Sejarah Perumusan Naskah Proklamasi dengan gaya semi realis yang dapat dipublikasikan ke remaja sebagai sebuah media informasi. Alasan pembuatan karakter ini sebagai sarana informasi mengenai Sejarah Perumusan Naskah Proklamasi karena pada zaman yang sudah canggih ini para remaja mulai beralih ke media digital, khususnya media sosial yang sedang digandrungi oleh para remaja. Selain itu, dengan pembuatan karakter ini pengenalan tokoh akan lebih mudah untuk dipahami oleh para remaja karena dikemas dengan media yang menarik yang disesuaikan dengan perkembangan zaman.

Tujuan dari perancangan karakter ini sebagai media pembelajaran dan media baca bagi remaja tentang Sejarah Perumusan Naskah Proklamasi sehingga remaja dapat mengetahui perjuangan saat perumusan Naskah Proklamasi serta dapat menambah pengetahuan dalam mengembangkan tingkat dan minat remaja untuk mempelajari sejarah Indonesia. Target dari perancangan karakter tokoh yang nantinya diaplikasikan dalam perancangan motion comic ini adalah kalangan remaja yang diharapkan dapat menarik perhatian mereka sebagai bentuk ketertarikannya mempelajari Sejarah Perumusan Naskah Proklamasi. Selain itu, dari perancangan karakter tokoh yang dibuat ini diharapkan dapat menjadi suatu media baca yang menginformasikan kepada remaja dan sebagai bentuk media pembelajaran baru yang menarik bagi remaja saat ini.

\section{METODE PENELITIAN}

Penelitian ini menggunakan metode kualitatif. Penelitian dengan metode kualitatif ini dilakukan dengan cara pengumpulan data melalui studi literatur, observasi, dan wawancara mendalam kepada narasumber yang berkaitan dengan objek penelitian.

Dalam teknik pengumpulan data sangat dibutuhkan literatur, seperti buku dan artikel jurnal yang layak digunakan sebagai bahan penelitian, agar mampu mengetahui peristiwa perumusan naskah proklamasi sampai akhirnya proklamasi di umumkan oleh Soekarno dan Muhammad hatta. Dalam observasi penulis melakukannya di Museum Perumusan Naskah Proklamasi yang berada di Jakarta. Dalam museum tersebut didapatkan literatur dan data berupa benda-benda, set ruangan, dan patung para tokoh yang terlibat dalam perumusan naskah proklamasi. Hal itu akan membantu peneliti membuat media sebagai referensi visual.

Untuk memperkuat data penulis setelah melakukan studi pustaka dan observasi, dilakukan juga wawancara. Wawancara dilakukan dengan bertanya langsung kepada dosen sejarah yang memiliki kredibilitas mengenai sejarah perumusan naskah proklamasi. 


\section{HASIL DAN PEMBAHASAN}

Tahun 1945 adalah tahun yang sangat ditunggu-tunggu oleh bangsa Indonesia, pada tahun itulah bangsa Indonesia mampu merebut kemerdekaannya dari para penjajah yang selama bertahun-tahun menjajah bangsa Indonesia.

Naskah Proklamasi dirumuskan pada tanggal 17 Agustus 1945, hal ini diputuskan setelah Soekarno dan Hatta berdebat dengan Nishimura bahwa PPKI tidak boleh menyelenggarakan rapatnya karena Indonesia berada dalam status quo. Akhirnya, Soekarno dan Hatta sampai pada kesimpulan seperti yang diharapkan golongan muda bahwa Indonesia harus merdeka tanpa Jepang. Kemudian, perumusan naskah proklamasi dilakukan di rumah dinas Laksamana Maeda pada 17 Agustus 1945 dinihari (Suryo \& Ipong, 2011: 104 - 105).

Menurut Muhammad Hatta dalam bukunya yang berjudul Sekitar Proklamasi, setelah duduk sebentar sambil menceritakan hal-hal yang diperdebatkan dengan Nishimura, Bung Karno dan saya mengundurkan diri ke sebuah ruang tamu kecil bersama-sama dengan Soebardjo Sukarni BM Diah dan Sayuti Melik. Beberapa orang duduk di sekitar sebuah meja dengan maksud untuk membuat sebuah teks ringkas tentang proklamasi kemerdekaan Indonesia. Namun, tidak seorang di antara mereka mempunyai teks resmi yang dibuat pada tanggal 22 Juni 1945, yang sekarang disebut Piagam Jakarta (Hatta, 1970: 57).

Bung Karno kemudian berkata "Saya persilahkan bung Hatta menyusun teks ringkas itu, sebab bahasanya saya anggap yang terbaik. Sesudah itu kita persoalkan Bersama-sama. Setelah kita memperoleh persetujuan, kita bawa kemuka sidang lengkap yang sudah hadir diruang tengah." Saya jawab: "Kalau saya mesti memikirkannya lebih baik Bung menuliskannya, saya mendiktekannya." Semuanya setuju kalau kalimat pertama diambil saja dari akhir alinea ketiga rencana Pembukaan undang-undang dasar mengenai proklamasi. Lalu kalimat pertama itu menjadi: "kami bangsa Indonesia dengan ini menyatakan kemerdekaan Indonesia.", tetapi saya katakan, kalimat itu hanya menyatakan kemauan bangsa untuk menentukan nasibnya sendiri. Sebab itu mesti ada kemplemennya yang menyatakan bagaimana caranya menyelenggarakan Revolusi Nasional. Lalu saya diktekan kalimat yang berikut: "hal-hal yang mengenai pemindahan kekuasaan dan lainlain diselenggarakan dengan cara sakasama dan dalam tempo yang sesingkat-singkatnya". Setelah bertukar pikiran sebentar, teks ini disetujui oleh kami berlima yang menjadi panitia kecil (Hatta, 1970: 59).

Secara keseluruhan, teks proklamasi mengesankan bahwa pemindahan kekuasaan itu dilaksanakan dengan damai. Pilihan kata lain yang diputuskan tanpa keraguan menegaskan itu: dengan cara saksama - tidak terburu-buru, tidak dengan paksaan, dan dalam tempo yang sesingkat-singkatnya. Ini kalimat bisa ditafsirkan sesuai kepentingan pihak Jepang dan Indonesia, bagi Jepang ini artinya itu bisa dilakukan sambil menunggu datangnya sekutu yang memang tak lama lagi, tetapi sebaliknya bagi Indonesia itu berarti harus jangka waktu sesingkat-singkatnya itu adalah sebelum Sekutu mendarat (Hatta, 1970: 56 - 60).

Bung karno meminta agar Sayuti Melik mengetik naskah proklamasi di ruang di bawah dekat dapur. Dengan ditemani oleh BM Diah. Namun, konsep naskah proklamasi itu tidak dapat langsung ditik karena di rumah Maeda tidak tersedia mesin tik. Untuk itu, Satzuki Mishima dengan mengendarai mobil jeep pergi ke kantor militer Jerman untuk meminjam mesin tik. Ada tiga perubahan yang dilakukan pada naskah terakhir. Pertama, kata "Tempoh" menjadi "Tempo"; kedua, kalimat "wakil-wakil bangsa Indonesia" pada bagian akhir diganti menjadi "atas nama bangsa Indonesia"; ketiga, cara menulis tanggal "Djakarta, 17-8-05" menjadi "Djakarta, hari 17 boelan 8 tahoen 05 ". Angka 05 adalah singkatan angka tahun 2605 Tarikh Sumera yang sama dengan 1945 Masehi. Konsep naskah proklamasi tulisan tangan Bung Karno ditinggal begitu saja oleh Sayuti Melik, kemudian BM Diah mengambilnya (Suryo \& Ipong, 2011: 111).

Untuk membuat karakter tokoh diperlukan landasan teori untuk menjaga keilmiahan dari sebuah karya. Untuk berikut disampaikan beberapa konsep yang nantinya dijadian landasan dalan perancangan. 


\section{Ilustrasi}

Ilustrasi adalah penggambaran sebuah benda secara manual atau vektor. Dalam infografis, dapat menggunakan ilustrasi untuk menyajikan anatomi sebuah benda atau untuk menambahkan daya tarik estetis (Lankow, 2014: 19).

Ilustrasi merupakan gambar yang dipergunakan untuk menerangkan atau mengisi sesuatu. Dalam desain grafis, ilustrasi merupakan subjek tersendiri yang memiliki alur sejarah serta perkembangan yang spesifik atas jenis kegiatan seni itu. Fungsi ilustrasi ialah memberi gambaran tokoh atau karakter dalam cerita serta menampilkan beberapa contoh item yang diterangkan dalam suatu buku pelajaran (Kusrianto, 2009: 15).

\section{Karakter Visual}

Karakter adalah watak, tabiat, sifat-sifat kejiwaan, akhlak atau budi pekerti yang membedakan seseorang dengan yang Iain (kbbi.web.id, diakses pada 14 Oktober 2018). Karakter didefinisikan sebagai cara berpikir dan berperilaku yang menjadi Ciri khas tiap individu untuk hidup dan bekerja sama, baik dalam lingkup keluarga, masyarakat, bangsa, maupun negara (Julianto, D., \& Mutiaz, I.R, 2014: 2).

Acuan perancangan adalah sosok karakter pada tampilan, kepribadian tokoh karakter yang sesuai dengan cerita, dan kemampuan rancangan karakter tersebut dalam mempresentasikan dalam bentuk visualnya. Beberapa komponen penting dalam mempertimbangkan perancangan karakter visual adalah gender, ras, keunikan pada penampilannya, menjaga kesederhanaan dalam bentuk yang rumit, dan karakter yang mudah diingat dan diidentifikasi saat melihatnya. (Saptodewo, 2016: 31)

\section{Gaya Semi Kartun}

Gaya gambar yang diaplikasikan merupakan gabungan realis dan cartoon, seperti karikatur, sebagai ciri yang paling khas, tetapi ada banyak pula gaya-gaya lainnya tergantung skill gambar realis dan cartoon yang digabungkan, dan ini merupakan level atau tingkatan dari comic artist itu sendiri. Aliran semi realis/semi kartun ini juga banyak sekali variasinya (Gumelar 2011: 13).

\section{Analisis Khalayak \\ Segmentasi}

Segmentasi dari perancangan katakter ini adalah anak-anak. Anak-anak merupakan awal generasi penerus bangsa yang sejak dini harus diajarkan tentang nasionalisme. Diharapkan dengan perancangan karakter ini anak-anak lebih termotivasi lagi dalam kehidupan berbangsa. Dan semakin bangga menjadi bangsa Indonesia. Berikut penjelasan segmentasi dari perancangan karakter:

\section{Demografis}

Secara demografis, segmentasi dari perancangan ini adalah:

1. Jenis Kelamin : Laki-laki dan perempuan

2. Usia : $12-17$ tahun

3. Pendidikan : Sekolah Dasar - Sekolah Menengah Pertama

Target sasaran di usia 12 - 17 tahun. Pada usia tersebut adalah masa penting bagi anak untuk menerima informasi sebanyak-banyaknya. Termasuk di dalamnya mengajarkan pada mereka tentang sejarah.

\section{Desain Karakter}

Sketsa Kasar

Pembuatan sketsa kasar adalah sebuah awalan untuk merancang karakter, dimana sebuah sketsa kasar masih berupa outline saja, belum diberikan sentuhan berupa warna, tetapi bentuk wajah dan postur tubuh tokoh sudah bisa terlihat pada sketsa kasar tersebut. Pembuatan sketsa kasar ini di lakukan langsung dengan teknik digital sehingga sketsa kasar yang dihasilkan berupa vector. 


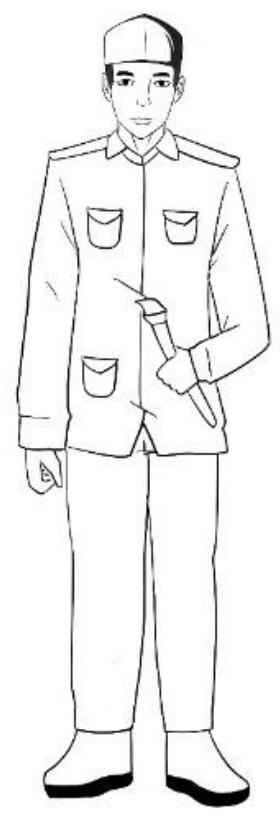

Gambar 1 Sketsa Karakter Soekarno

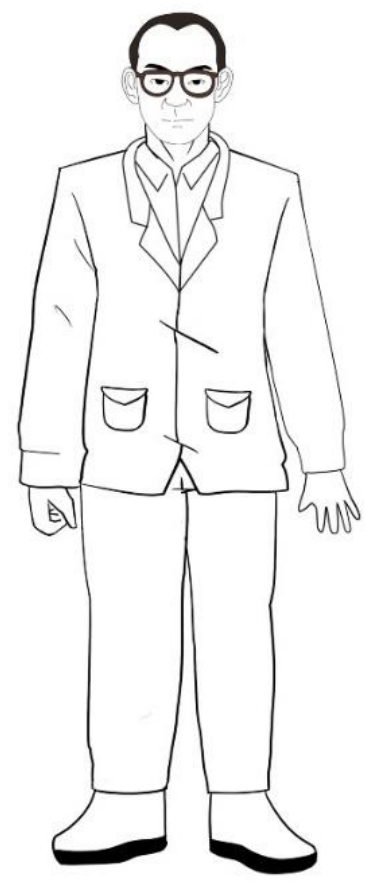

Gambar 2 Karakter M. Hatta 


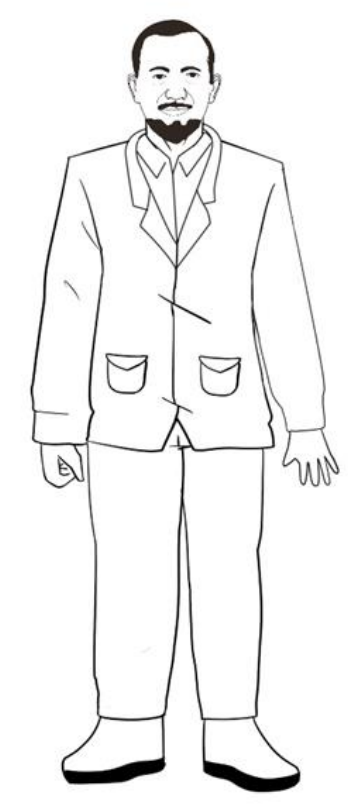

Gambar 3 Karakter Soebardjo

\section{Sketsa Halus}

Pada tahapan ini, desain karakter yang berupa outline diberikan sentuhan warna, pemberian shading dan detailing. Bisa disebut juga dengan finishing, agar tampilan karakter terlihat menarik dan lebih hidup. Finishing ini dilakukan menggunakan teknik tracing, menggunakan software Adobe Photoshop CS6. Dengan output JPEG.

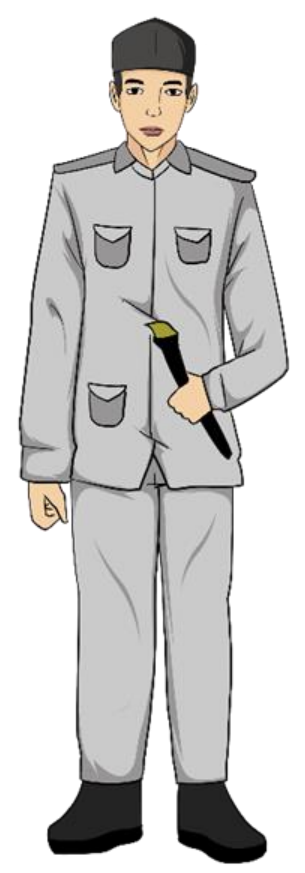

Gambar 4 Karakter Soekarno 


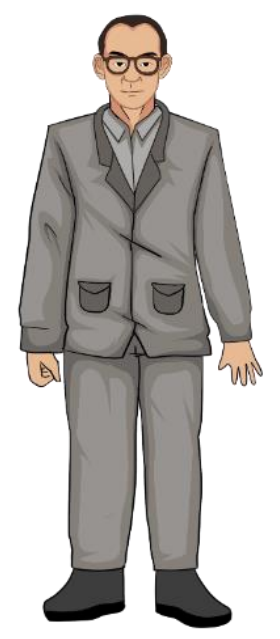

Gambar 5 Karakter M.Hatta

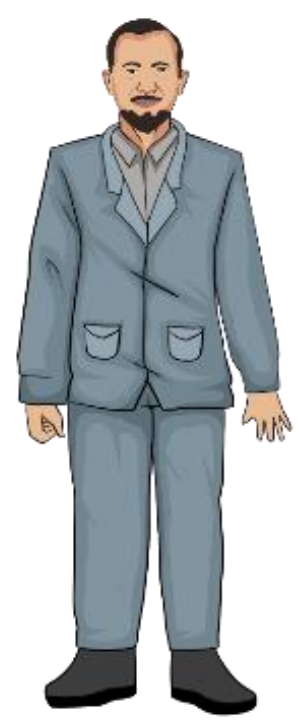

Gambar 6 Karakter Soebardjo

\section{Deskripsi Karya}

Warna yang digunakan dalam perancangan karakter ini adalah warna-warna yang disesuaikan dengan tema yang dipilih. Warna memiliki Bahasa komunikasi melalui visual atau indera penglihatan. Pilihan warna yang digunakan untuk perancangan karakter menggunakan komposisi dari warna pastel.

Warna pastel dipilih karena dianggap sesuai ketika digunakan dalam perancangan karakter ini karena warna pastel merupakan warna yang mengarah ke warna muda dari jenis warna atau warna cerah. Warna biru ketika bercampur dengan warna putih maka akan menjadi warna biru muda. Umumnya warna pastel terlihat lebih cerah, tetapi tidak begitu kuat warnanya 


\section{SIMPULAN}

Pada dasarnya sejarah adalah rangkaian perjuangan umat manusia dalam rangka perjuangan mempertahankan eksistensinya dan untuk mencapai cita-citanya. Demikian pula halnya dengan perjuangan bangsa Indonesia. Sejak "bangsa Indonesia" mulai ada, sejak itu pula perjuangan bangsa telah ada.

Perancangan karakter tokoh proklamator bangsa Indonesia dengan teknik digital bertujuan untuk memperkenalkan tokoh pahlawan bangsa Indonesia dalam hal ini adalah tokoh proklamator Indonesia. Ini adalah sebuah materi yang penting untuk dibahas karena agar para remaja tidak hanya mengetahui kapan proklamasi bangsa Indonesia berlangsung, tetapi siapa saja tokoh yang merancang atau merumuskan naskah proklamasi dan siapa yang memprokamirkannya.

Karakter tokoh proklamator dirancang dengan gaya visual semi kartun dengan mengacu pada data visual, seperti patung dan data gambar pada literatur, agar perancangan karakter tidak terlampau jauh pada tokoh aslinya.

\section{DAFTAR PUSTAKA}

Suryo, A, \& Ipong, J. (2011). Detik-detik proklamasi. Jakarta: Narasi.

Hatta, M. (1970). Sekitar proklamasi. Jakarta: Tintamas.

Gumelar, M. S. (2011). Cara membuat komik. Jakarta: PT Indeks

Julianto, D., \& Mutiaz, I.R. (2014). Perancangan serial animasi 3D “Steven's Habits" Sebagai Media Pendidikan Karakter Yang Efektif Untuk Anak Melalui Prinsip 7 Habits. Fakultas Seni Rupa dan Desain ITB. Bandung.

Lankow J. (2014) Infographics: Kedahsyatan cara bercerita visual. Jakarta: Gramedia

Fathoni, R, S. (2017). Sejarah Pengeboman Hiroshima dan Nagasaki (1945 M). [Online]. Diakses dari http://wawasansejarah.com/sejarah-pengeboman-hiroshima-dan-nagasaki/.

Saptodewo, F. (2016). Perancangan Karakter Wayang Tetuka untuk Lanjutan Cerita Saat Keluar dari Kawah Candradimuka. Jurnal Desain, 4(01), 29-37. 